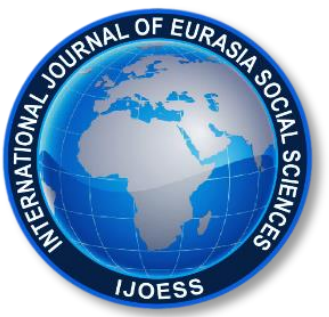

International Journal of Eurasia Social Sciences

Vol: 11, Issue: 40, pp. (519-529).

Article Type: Research Article

Received:27.12.2019

Accepted:16.05.2020

Published:07.06.2020

\title{
OBESITY AWARENESS LEVELS OF PUBLIC AND PRIVATE LOWER-SECONDARY SCHOOL STUDENTS
}

\author{
Funda COŞKUN ÖZYOL \\ Dr., Van Yüzüncü Yıl University, Turkey, fcoskun@yyu.edu.tr \\ ORCID: 0000-0003-0198-4331
}

\begin{abstract}
The purpose of this study is to examine whether the obesity awareness levels of lower-secondary school students differ according to school type and gender, and whether there is a relationship between the level of awareness and the body mass indexes of students. The population of this study is the 12-14 years old lower-secondary school students. A total of 590 students were included in the study this study. The mean ages of the female students were $13.0 \pm .9$ and male students were 13.0 \pm 1.0. Demographic Information Form, Obesity Awareness Scale and BMI measurements were used to collect data. Independent $t$-test and Pearson's correlation coefficient was used to analyze data. Results of the data analysis showed statistically no significant difference between the public and private lower-secondary school students' obesity awareness levels. The only difference found between the students' BMI levels. Results also showed statistically no significant difference between female and male students' obesity awareness levels. Correlation analysis revealed a non-significant correlation between BMI and obesity awareness scores of female and male lower-secondary school students. The study findings showed that obesity awareness were similar in public and private lower-secondary school students, and did not correlate with BMI level of students.
\end{abstract}

Keywords: Lower-secondary level, obesity awareness, BMI, adolescent. 


\section{INTRODUCTION}

Since the 1970s, the prevalence of obesity has increased almost three times in adults, but in recent years the increase in children and adolescents has become much more noticeable. Obesity is known as a disease caused by excessive increase in adipose tissue in the body as a result of imbalance between energy intake and expenditure. Obesity, which is accompanied by overweight and excessive fat, is among the most important health problems of developed and developing countries today and its frequency is increasing gradually. According to the World Health Organization (WHO) (2020), obesity is defined as "abnormal or excessive fat accumulation that poses a risk to health". On the other hand, the World Obesity Federation, which does not agree with the view that obesity is only a risk factor for diseases, defines obesity as a chronic, relapsing progressive disease. Obesity among children and adolescents is a major public health problem worldwide. The study titled "The Health Behavior in School-aged Children (HBSC)" was conducted between 2009-2010 years in 39 countries of the European Union. In this study, the body weight and height of adolescents between the ages of $11-15$ were measured, and results demonstrated that $15 \%$ of 11 -year-old students, $14 \%$ of 13 -year-old students and $14 \%$ of 15 -year-old students were overweight and obese (HBSC, 2009). Around the same years, according to the results of the National Nutrition and Health Research (NHANES) of the United States, $16.9 \%$ of the child and adolescent population was reported to be obese (15\% in girls and $18.6 \%$ in boys) and this value was approximately 12.5 million (National Center for Health Statistics [NCHS], 2012). Considering the studies conducted across the country, $14.2 \%$ of children between the ages of $6-9$ were reported to be overweight, 8.3\% were obese, according to the renewed study results that in 2016-2017 the number of overweight children has been reported to increase to $14.6 \%$, and obese children to $9.9 \%$ (Childhood Obesity Surveillance InitiativeTurkey [COSI-TUR], 2017). The increase in obesity among children and adolescents in the form of epidemic disease has become an alarming picture for the future adult community (WHO, 2010).

Obesity, which is affected by genetic and non-genetic factors, is defined as a complex multi-factorial disease. When the etiology of obesity is examined, it is stated that the causes of obesity was unhealthy diet (meal skipping, fast food, alcohol, etc.) resulting from the imbalance between excessive energy intake and expenditure, physical inactivity, and the inadequacy of the state policies towards the food and education sector. Nutritional and physical activity habits acquired in childhood and adolescence for a healthy development process may have very important reflections especially in terms of physical and emotional states (King, Wold, Tudor-Smith, Harel \& Waterson, 1997). It is reported that food consumption especially during adolescence is associated with some of the common diseases such as obesity, anorexia and bulimia (Nielsen, Siega-Riz \& Popkin, 2002). It is suggested that children at risk and adolescents should be encouraged to prevent healthy intervention strategies and healthy eating and regular physical activity habits (MacKenzie, 2000). For this reason, the prevalence of obesity should be determined in a short time, accurately and economically, especially in childhood and adolescent period, and prevention-prevention and treatment programs should be organized and implemented (Al-Rethaiaa, Fahmy \& Al-Shwaiyat, 2010). In order to increase the effectiveness of these programs, it is of great importance to identify the problem in the early period from a social perspective. 
Some of the methods that are frequently used in the definition and monitoring of obesity are easy, feasible and high accuracy rates such as Body Mass Index (BMI), bioelectric impedance analysis, waist circumference, hip circumference and waist hip ratio (Can, 2019).

When the literature is examined, it is proved that there is a strong relationship between $\mathrm{BMI}$ and perception of weight in children and adolescents. It was also observed that this relationship had an effect on weight loss (Gillison, Standage \& Skevington, 2006). According to the results of the study conducted by Swallen, Reither, Haas and Meier (2005), it was reported that there was a relationship between BMI and both general and physical health, and it was also concluded that overweight children and adolescents feel more personally negative than their normal weight peers. In a similar study, an inverse correlation was found between BMI and children's personal well-being (Tsiros et al., 2009). In addition, regarding the perception of weight, girls have been reported to perceive themselves as overweight than boys (Martin, Frisco \& May, 2010). In this context, some studies have been carried out to evaluate the obesity awareness of the society and to prevent the incidence of obesity from increasing. Murphy and Polivka (2007) investigated the obesity and BMI awareness of parents of school-age students. Li and Hooker (2010) investigated the relationship between obesity prevalence and school type according to the BMI values obtained by measuring height and weight of students studying in private and public schools in 2003-2004. Fahlman, Dake, McCaughtry and Martin (2008) investigated the effect of Michigan Model, a nutritional education program, on students' nutritional awareness and habits. Lee, Lai, Chou, Chang and Chang (2009) evaluated physical perception of students by applying physical activity program to obese students in 11 different groups. As a result of the research, the participants' perception of physical activity improved positively with the training program they received. In Turkey, research on obesity awareness of secondary school students is limited.

As literature suggests that the prevalence of obesity in the adolescent period, which covers the secondary school education period, has reached an epidemic rate around the world by increasing approximately 4 times in the last 35 years, the childhood and adolescent obesity is an important public health problem worldwide, childhood and adolescent obesity is an important public health problem worldwide and children, and children and adolescents are also affected by obesity threat in Turkey. It is thought that an important reason for this situation is due to the low awareness level of children and adolescents towards obesity. Although there are large-scale studies on the prevalence of obesity, there are almost no studies showing the awareness of children and young people about obesity. Considering that the adolescent period is an important transition period from childhood to adolescence, it is thought that the measurement of obesity awareness levels of students will be helpful to prevent obesity and protect children and adolescent from obesity in the future. Therefore, the aim of this study is to examine whether the obesity awareness levels of secondary school students differ according to school type (state, private) and gender (female, male) variables and whether there is a relationship between the level of awareness and the body mass indexes of students. 


\section{METHOD}

\section{Research Design}

In this study, correlational and cross-sectional research designs were used. Correlational research design examines the degree of the existence and/or degree of change between two or more variables (Fraenkel, Wallen \& Hyun, 2012).

\section{Population and Sample}

The population of this study is the secondary school students in the Ijpekyolu district of Van, and the sample is 12-14 years old students in a public and a private secondary school. The mean ages of the female and male students were $13.0 \pm .9$ and $13.0 \pm 1.0$, respectively. A total of 590 students were included in the study this study and distributed $48.6 \%$ female and $51.4 \%$ male. Sixty-one percent of the 362 participants attended public school and $39 \%$ private school. In addition to the permissions obtained from the official institutions, the "Informed Consent Form" was obtained from the families of the students who volunteered to participate in the study. Before this permission, the contact information of the families of the students who volunteered to participate in the research was obtained, necessary appointments were made, and the families were informed about the study.

\section{Data Collection Instruments}

\section{Demographic Information Form}

In order to obtain demographic information from the students participating in the research, Demographic Information Form containing age, gender (female, male) and school type (public school, private school) questions was used.

\section{Obesity Awareness Scale}

The "Obesity Awareness Scale" was used in this research to find out the obesity awareness level of secondary school students participating in the study. The scale was originally developed by Allen (2011) and translated to Turkish by Kafkas and Özen (2014). The scale consists of 21 items and three subscales: "obesity awareness (8 items)", "nutrition awareness (7 items)", and "physical activity awareness (8 items)". The scale was prepared in 4-point Likert type and statements on the scale are sorted from positive to negative. The internal consistency coefficient obtained during the development of the original scale was calculated as .80 , and obtained during the translation to Turkish was calculated as .87 , and it was calculated as .75 in this study. 


\section{Body Mass Index (BMI) Measurement}

Anthropometric measurements (body weight and height) of the students were measured to determine the BMI. Body weight measurement, which is one of these measurements, was taken using an electronic scale on a flat surface, and students' feet were bare and lightly dressed, and the heights were measures with stadiometer with accuracy of $\pm 1 \mathrm{~mm}$. The BMI of the students was calculated by placing the body weight and height values in the formula of dividing the body weight $(\mathrm{kg})$ by the square of the height $(\mathrm{m})$. Using the data obtained, the BMI value and percentile value of each participant were calculated according to the formula below. These values were then converted into $z$ values and included in the analysis within the scope of the study.

\section{Data Analysis}

The data obtained as a result of the measurements were transferred to the computer and IBM SPSS 23 (Statistical Package for Social Sciences) package program was used for analysis. The distribution of the data was examined with the Kolmogorov-Smirnov test and it was determined that the students' obesity awareness total scores, obesity awareness, nutritional awareness, physical activity awareness scores, and BMI values showed normal distribution. Therefore, in order to determine whether students' obesity awareness total score and subdimensions score and BMI values differ according to school type and gender variables, an independent $t$-test; and to determine whether there is a significant relationship between obesity awareness total score and subdimension scores and BMI values Pearson's correlation coefficient was used.

\section{FINDINGS (RESULTS)}

Independent t-test was applied to determine whether there is a statistically significant difference between obesity awareness total scores, obesity awareness, nutritional awareness and physical activity awareness subscale scores and BMI values of secondary school students participating in the study. The results of the analysis showed that there is no statistically significant difference between the obesity awareness total scores $\left[\left(\bar{x}_{\text {public }}=57.31, S D_{\text {public }}=7.98 ; \bar{x}_{\text {private }}=58.12, S D_{\text {private }}=7.47\right), t(588)=-1.24, p=.22\right]$, obesity awareness $\left[\left(\bar{x}_{\text {public }}=\right.\right.$ 25.14, $\left.\left.S D_{\text {public }}=4.30 ; \bar{x}_{\text {private }}=25.10, S D_{\text {private }}=4.03\right), t(588)=.13, p=.90\right]$, nutrition awareness $\left[\left(\bar{x}_{\text {public }}=18.13\right.\right.$, $\left.\left.S D_{\text {public }}=3.33 ; \bar{x}_{\text {private }}=18.63, S D_{\text {private }}=3.37\right), t(588)=-1.76, p=.08\right]$, and physical activity awareness $\left[\left(\bar{x}_{\text {public }}=\right.\right.$ 14.03, $\left.S D_{\text {public }}=2.31 ; \bar{x}_{\text {private }}=14.39, S D_{\text {private }}=2.36\right), t(588)=-1.83, p=.07$ ] subscale scores of the students studying in public and private secondary school, but when the BMI values are examined, the BMI values of the public school students $(\bar{x}=18.45, S D=3.26)$ are lower than the private school students $(\bar{x}=20.71, S D=4.05)$, $t(588)=-7.47, p=.001$ (Table 1$)$. 
Table 1. Comparison of Participants' Obesity Awareness Total and Sub-Dimension Scores and BMI Values by School Type

\begin{tabular}{lcccccc}
\hline & \multicolumn{3}{c}{$\begin{array}{c}\text { Public School } \\
(n=382)\end{array}$} & \multicolumn{2}{c}{$\begin{array}{c}\text { Private School } \\
(n=228)\end{array}$} \\
\hline & $\bar{x}$ & $S D$ & $\bar{x}$ & $S D$ & $t$ & -1.24 \\
\hline Obesity Awareness Total Score & 57.31 & 7.98 & 58.12 & 7.47 & .13 & -1.76 \\
Obesity Awareness & 25.14 & 4.30 & 25.10 & 4.03 & 3.37 & -1.83 \\
Nutrition Awareness & 18.13 & 3.33 & 18.63 & 14.39 & 2.36 & $-7.47^{*}$ \\
Physical Activity Awareness & 14.03 & 2.31 & 3.26 & 20.71 & 4.05 &
\end{tabular}

$* p<.001$

Independent $t$-test was applied to determine whether there is a statistically significant difference between obesity awareness total scores, obesity awareness, nutritional awareness and physical activity awareness subscale scores and BMI values of female and male secondary school students participating in the study. Since the BMI values of students studying in public and private secondary schools differed in the previous analysis, the data were divided according to two school types and then were analyzed. The results of the analysis revealed that there is no statistically significant difference between the obesity awareness total scores [( $\bar{x}_{f e m a l e}=$ $\left.\left.57.40, S D_{\text {female }}=8.17 ; \bar{x}_{\text {male }}=57.19, S D_{\text {male }}=7.76\right), t(360)=.26, p=.80\right]$, obesity awareness $\left[\left(\bar{x}_{\text {female }}=25.31, S D_{\text {female }}=\right.\right.$ 4.39; $\left.\left.\bar{x}_{\text {male }}=24.92, S D_{\text {male }}=4.18\right), t(360)=.85, p=.40\right]$, nutrition awareness $\left[\left(\bar{x}_{\text {female }}=18.04, S D_{\text {female }}=3.31 ; \bar{x}_{\text {male }}=\right.\right.$ $\left.\left.18.25, S D_{\text {male }}=3.37\right), t(360)=-.59, p=.56\right]$ and physical activity awareness $\left[\left(\bar{x}_{\text {female }}=14.05, S D_{\text {female }}=2.24 ; \bar{x}_{\text {male }}=\right.\right.$ 14.01, $\left.\left.S D_{\text {male }}=2.41\right), t(360)=.15, p=.88\right]$ sub-dimension scores and BMI values of female $\left(\bar{x}_{\text {female }}=18.71, S D_{\text {female }}=\right.$ 3.61); and male $\left(\bar{x}_{\text {male }}=18.11, S D_{\text {male }}=2.72\right)$ students studying at public school, $t(360)=1.74, p=.08$ (Table 2$)$. In addition, the results of the analysis revealed that there is no statistically significant difference between the obesity awareness total scores $\left[\left(\bar{x}_{\text {female }}=59.25, S D_{\text {female }}=6.99 ; \bar{x}_{\text {male }}=57.46, S D_{\text {male }}=7.68\right), t(226)=1.75, p=.08\right]$, obesity awareness $\left[\left(\bar{x}_{\text {female }}=25.86, S D_{\text {female }}=3.81 ; \bar{x}_{\text {male }}=24.65, S D_{\text {male }}=4.10\right), t(226)=2.22, p=.07\right]$, nutrition awareness $\left[\left(\bar{x}_{\text {female }}=18.69, S D_{\text {female }}=3.05 ; \bar{x}_{\text {male }}=18.60, S D_{\text {male }}=3.56\right), t(226)=.20, p=.84\right]$ and physical activity awareness $\left[\left(\bar{x}_{\text {female }}=14.70, S D_{\text {female }}=2.13 ; \bar{x}_{\text {male }}=14.22, S D_{\text {male }}=2.47\right), t(226)=1.49, p=.14\right]$ subscale scores and BMI values of the female $\left(\bar{x}_{\text {female }}=20.25, S D_{\text {female }}=3.23\right)$, and male students $\left(\bar{x}_{\text {male }}=20.98, S D_{\text {male }}=4.46\right)$ studying in private school, $t(226)=-1.32, p=.19$ (Table 2$)$. 
Table 2. Comparison of Participants' Obesity Awareness Total and Sub-Dimension Scores and BMI Values by School Type and Gender

\begin{tabular}{|c|c|c|c|c|c|}
\hline & \multicolumn{2}{|c|}{ Female } & \multicolumn{2}{|c|}{ Male } & \multirow[b]{2}{*}{$t$} \\
\hline & $\bar{x}$ & $S D$ & $\bar{x}$ & $S D$ & \\
\hline \multicolumn{6}{|l|}{ Public School } \\
\hline Obesity Awareness Total Score & 57.40 & 8.17 & 57.19 & 7.76 & .26 \\
\hline Obesity Awareness & 25.31 & 4.39 & 24.92 & 4.18 & .85 \\
\hline Nutrition Awareness & 18.04 & 3.31 & 18.25 & 3.37 & -.58 \\
\hline Physical Activity Awareness & 14.05 & 2.24 & 14.01 & 2.41 & .15 \\
\hline BMI & 18.71 & 3.61 & 18.11 & 2.72 & 1.74 \\
\hline \multicolumn{6}{|l|}{ Private School } \\
\hline Obesity Awareness Total Score & 59.25 & 6.99 & 57.46 & 7.68 & 1.75 \\
\hline Obesity Awareness & 25.86 & 3.81 & 24.65 & 4.10 & 2.22 \\
\hline Nutrition Awareness & 18.69 & 3.05 & 18.60 & 3.56 & .20 \\
\hline Physical Activity Awareness & 14.70 & 2.13 & 14.22 & 2.47 & 1.49 \\
\hline BMI & 20.25 & 3.23 & 20.98 & 4.46 & -1.32 \\
\hline
\end{tabular}

Pearson correlation coefficient was applied to examine whether there is a statistically significant relationship between obesity awareness total scores, obesity awareness, nutrition awareness and physical activity awareness subscale scores and BMI values of the female and male students studying at public and private secondary schools. However, as mentioned earlier, since the BMI values of students studying in public and private schools are different, the data were divided by school type and analyzes were made. The results of the analysis revealed that there is no statistically significant relationship between BMI values of students studying in both public and private secondary schools and total scores of obesity awareness ( $r_{\text {public }}=-.056, p_{\text {public }}=.28$; $\left.r_{\text {private }}=.015, p_{\text {private }}=.82\right)$, obesity awareness ( $\left.r_{\text {public }}=-.090, p_{\text {public }}=.09 ; r_{\text {private }}=.056, p_{\text {private }}=.40\right)$, nutrition awareness ( $r_{\text {public }}=-.079, p_{\text {public }}=.13 ; r_{\text {private }}=-.032, p_{\text {private }}=.07$ ) and physical activity awareness sub-dimensions $\left(r_{\text {public }}=.086, p_{\text {public }}=.10 ; r_{\text {private }}=-.002, p_{\text {private }}=.98\right)($ Table 3$)$. 
Table 3. Relationship between Participants' BMI Values and Obesity Awareness Total and Sub-Dimension Scores

\begin{tabular}{lc}
\hline & BMI \\
\hline Public School ( $n=361)$ & $r$ \\
\hline Obesity Awareness Total Score & -.056 \\
Obesity Awareness & -.090 \\
Nutrition Awareness & -.079 \\
Physical Activity Awareness & .086 \\
\hline Private School ( $n=228)$ & .015 \\
\hline Obesity Awareness Total Score & .056 \\
Obesity Awareness & -.032 \\
Nutrition Awareness & -.002 \\
Physical Activity Awareness & \\
\hline
\end{tabular}

\section{DISCUSSION and CONCLUSION}

In the current study, it was aimed to examine whether the obesity awareness levels of the students studying at the secondary school level differ according to the type of school (private school, state school) and gender (female, male), and whether the level of awareness is related to BMI. As a result of the research, the obesity awareness total scores, obesity awareness, nutrition awareness and physical activity awareness sub-dimension scores of the students studying in private and public schools did not differ, and the scores obtained from obesity awareness total scores and sub-dimensions of female and male adolescents did also not differ. Finally, no statistically significant relationship was found between the students' obesity awareness total score, obesity awareness, nutrition awareness and physical activity awareness sub-dimension scores, and the BMI of the students. This is supported by research findings that of Atlı, Özkan and Uyar (2016) that examining the levels of secondary school students obesity awareness. Researchers revealed that there is no statistically significant difference between the obesity awareness total scores and obesity awareness, nutrition awareness and physical activity awareness sub-dimension scores of young female and male students. In another study Alasmari, Al-Shehri, Aljuaid, Alzaidi and Alswat (2017) examined the prevalence of overweight and obesity in intermediate and high school students and whether this prevalence is related to obesity awareness level. Researchers found that $25.4 \%$ of students participating in the study had high levels of awareness of obesity and similar to the findings of this study, it also found that there was no relationship between students' BMI and obesity awareness level. In another study conducted in the adolescent sample, Yüksel and Akıl (2019) examined the obesity awareness levels of adolescents and found that the obesity awareness levels of adolescents participating in the study were moderate and there was a significant relationship between the adolescents' level of obesity awareness and physical activity. Yüksek (2019), who examined the obesity awareness level of adolescents, revealed that the obesity awareness level of the participants is at a medium level, and in addition to this, obesity awareness levels of female adolescents were found to be higher in both obesity awareness and sub-dimensions than male adolescents. Günay-Kara (2017), who examined the physical activity and obesity 
awareness levels of secondary school students, revealed that the obesity awareness levels of secondary school students were below the average level, and study findings also showed that the obesity awareness levels of students do not differ by gender. In an experimental study conducted for obesity awareness level in adolescents, Akgül-Ertan (2019) stated that health related knowledge and exercise programs to be given will increase adolescents' level of obesity awareness. In another study that examined the relationship between BMI and obesity awareness level, Özkan, Adıbelli, İlaslan and Taylan (2020) examined the obesity awareness levels of university students and found that the total score obtained from the obesity awareness scale and obesity awareness sub-dimensions did not differ according to gender or the participants. In addition, the researchers revealed that there was no statistically relationship between the obesity awareness total score and the obesity awareness sub-dimensions and the students' BMI values. Sözen and Bebek (2018) conducted a research on obesity awareness and related variables among university students, and found that obesity awareness levels of university students do not differ by gender and obesity awareness levels of female and male students are similar. In another study examining the obesity awareness level of university students Genç and Tunç (2019) found that the obesity awareness level of the students was above the middle level, however, in line with the findings of this study, it was found that the obesity awareness level did not differ by gender.

In conclusion, findings of the current study demonstrated that the obesity awareness levels of public and private lower-secondary school female and male students were not different and obesity awareness level did not correlate with BMI levels of students. It has also been observed that the studies in the literature reviewed are in line with this research finding. Based on these results, it is recommended to organize obesity related seminars and training programs in order to increase the obesity awareness levels of both female and male students to higher levels. Future studies may focus on examining primary, upper secondary and high school students' obesity awareness levels and related variables.

\section{ETHICAL DECLERATION}

"In this article, journal writing rules, publishing principles, research and publishing ethics rules, journal ethics rules are followed. Responsibility belongs to the author for any violations related to the article."

\section{REFERENCES}

Akgül-Ertan, G. (2019). The effects of aerobic exercises and healthy life education on nutrition, physical activity and obesity awareness for students between the ages of 12-14. Unpublished Master's Thesis. Van Yüzüncü Yıl University. Faculty of Educational Sciences.

Alasmari, H. D., Al-Shehri, A. D., Aljuaid, T. A., Alzaidi, B. A. \& Alswat, K. A. (2017). Relationship between body mass index and obesity awareness in school students. Journal of Clinical Medicine Research, 9(6), 520524.

Allen A. (2011). Effects of educational intervention on children's knowledge of obesity risk factors. Carroll College, Department of Health Sciences, Undergraduate Thesis. 
Al-Rethaiaa, A. S., Fahmy, A. A. \& Al-Shwaiyat, N. M. (2010). Obesity and eating habits among college students in Saudi Arabia: A cross sectional study. Nutrition Journal, 9(1), 39.

Atlı, M., Özkan, Z. \& Uyar, B. (2016). Assessment of obesity awareness stage of secondary school students. In SHS Web of Conferences, 31, 01004.

Can, S. (2019). Physical activity measurement: Objective and subjective methods. Spor Hekimliği Dergisi, 54(4), 296-307.

Childhood Obesity Surveillance Initiative-Turkey [COSI-TUR]. (2017). Türkiye Çocukluk Çağı (ilkokul 2. Sınıf Öğrencileri) Şişmanlık Araştırması - COSı-TUR 2016. Sağıık Bakanlığı, Halk Sağlığı Genel Müdürlüğü, Milli Eğitim Bakanlığı, Dünya Sağlık Örgütü Avrupa Bölge Ofisi, Sağlık Bakanlığı Yayın No: 1080, Ankara.

Fahlman, M., Dake, J., McCaughtry, N. \& Martin, J. (2008). A pilot study to examine the effects of a nutrition intervention on nutrition knowledge, behaviors, and efficacy expecations in middle school children. Journal of School Health, 78(4), 216-222.

Fraenkel, J. R., Wallen, N. E. \& Hyun, H. H. (2012). How to design and evaluate research in education (8th ed.). New York: McGraw-Hill.

Genç, A. \&Tunç, A. Ç. (2019). Examination of obesity awareness levels of physical education teacher and coaching education. Journal of Education and Training Studies, 8(2), 24-28.

Gillison, F. B., Standage, M. \& Skevington, S. M. (2006). Relationships among adolescents' weight perceptions, exercise goals, exercise motivation, quality of life and leisure-time exercise behavior: A selfdetermination theory approach. Health Education Research, 21(6), 836-847.

Günay-Kara, M. (2017). Investigation of physical activity levels and obesity awareness levels of middle school students. Unpublished Master's Thesis. İnönü University. Institute of Health Sciences.

Kafkas, M. E. \& Özen, G. (2014). The Turkish adaptation of the Obesity Awareness Scale: A validity and reliability study. Inönü Üniversitesi Beden Eğitimi ve Spor Bilimleri Dergisi, 1(2), 1-15.

King, A., Wold, B., Tudor-Smith, C., Harel, Y. \& Waterson, T. (1996). The health of youth: A cross-national survey. Developmental Medicine and Child Neurology, 39(7), 495-495.

Lee, P., Lai, H., Chou, Y., Chang, L. \& Chang, W. (2009). Perceptions of exercise in obese school-aged children. Journal of Nursing Research, 17(3), 170-176.

Li, J. \& Hooker, N. H. (2010). Childhood obesity and schools: Evidence from the national survey of children's health. Journal of School Health, 80(2), 96-103

MacKenzie, N. (2000). Childhood obesity: Strategies for prevention. Pediatric Nursing, 26(5), 527-530.

Martin, M. A., Frisco, M. L. \& May, A. L. (2009). Gender and race/ethnic differences in inaccurate weight perceptions among US adolescents. Womens Health Issues, 19(5), 292-299.

Murphy, M. \& Polivka, B. (2007). Parental perceptions of the school's role in addressing childhood obesity. The Journal of School Nursing, 23(1), 40-46.

NCD Risk Factor Collaboration (NCD-RisC) (2017). Worldwide trends in body-mass index, underweight, overweight, and obesity from 1975 to 2016: A pooled analysis of 2416 population-based measurement studies in 128.9 million children, adolescents, and adults. Lancet, 390, 2627-2642. 
National Center for Health Statistics [NCHS]. (2012). Obesity research. Retrieved from http://www.cdc.gov/nchs/ data/databriefs/ db82.pdf.

Nielsen, S., Siega-Riz, M. \& Popkin, M. (2002). Trends in food locations and sources among adolescents and young adults. Preventive Medicine, 35(2), 107-113.

Özkan, I., Adıbelli, D., Illaslan, E., \& Taylan, S. (2020). Relationship between body mass index and obesity awareness of university students. Acıbadem Üniversitesi Sağlık Bilimleri Dergisi, 11(1), 120-126.

Sozen, H. \& Bebek, G. (2018, June). Üniversite öğrencilerinin obezite farkındalığının belirlenmesi. $5^{\text {th }}$ International Congress on Politic, Economic and Social Studies (ICPESS), Niğde, Turkey.

Swallen, K. C., Reither, E. N., Haas, S. A. \& Meier, A. M. (2005). Overweight, obesity, and health-related quality of life among adolescents: the national longitudinal study of adolescent health. Pediatrics, 115(2), 340347.

Tsiros, M. D., Olds, T., Buckley, J. D., Grimshaw, P., Brennan, L., Walkley, J., Hills, A. P., Howe, P. R. \& Coates, A. M. (2009). Health- related quality of life in obese children and adolescents. International Journal of Obesity, 33(4), 387-400.

World Health Organisation [WHO]. (2010). Global strategy on diet, physical activity and health. Retrieved from https://www.who.int/dietphysicalactivity/strategy/eb11344/strategy_english_web.pdf

World Health Organization [WHO]. (2016). Obesity and overweight: Key facts. Retrieved from https://www.who.int/en/news-room/fact-sheets/detail/obesity-and-overweight

World Health Organization [WHO]. (2020). Health topics: Obesity. Retrieved from https://www.who.int/topics/obesity/en/

Yüksel, E. (2019). Evaluation of physical activity, awareness of obesity and dietary behaviors among adolescents. Unpublished Master's Thesis. Uşak University, Institute of Health Sciences.

Yüksel, E. \& Akıl, M. (2019). Investigation of the correlation between the physical activity levels of adolescents and their awareness about obesity and nutritional behaviors. Beden Eğitimi ve Spor Bilimleri Dergisi, 13(3), 185-193. 